\title{
Intencionalidade: estrutura necessária a uma psicologia em bases fenomenológicas.
}

\section{Intentionality: necessary structure for a psychology in phenomenological bases.}

\section{Roberto S. KahImeyer-Mertens*}

Universidade do Estado do Rio de Janeiro - UERJ, Rio de Janeiro, Rio de Janeiro, Brasil

\begin{abstract}
RESUMO
O artigo toma por tema o conceito de intencionalidade. Questiona a posição deste conceito no âmbito de uma psicologia fundada em bases fenomenológicas. Para respondermos a esta questão, objetivamos apresentar o conceito de intencionalidade segundo a fenomenologia, reconstruir brevemente sua gênese histórica nas filosofias de Brentano, Husserl e Heidegger e indicar a importância deste conceito em autores da assim chamada Daseinanalyse (Binswangen e Boss). Abordada fenomenologicamente, tomamos a intencionalidade como traço fundamental de uma consciência; julgamos poder sustentar que esta estrutura viabiliza uma interpretação do psiquismo diversa daquela promovida pela leitura tradicional que reduz a consciência a sujeito. Considerando a intencionalidade a estrutura que permite a correlação imediata da consciência com seus fenômenos, julgamos lícito afirmar que uma Daseinanalyse, entendida como psicologia e psicopatologia fenomenológica, apenas se viabiliza no espaço aberto pela consciência intencional.
\end{abstract}

Palavras-chave: consciência, intencionalidade, Daseinanalyse, Heidegger.

\section{ABSTRACT}

The article takes the concept of intentionality as theme. We inquired into the position of this concept in the context of a phenomenological psychology. To answer this question, we aim to introduce the concept of intentionality according to Phenomenology, briefly reconstruct its historical genesis in the philosophies of Brentano, Husserl and Heidegger, and indicate the importance of this concept in the so-called Daseinanalyse (Binswangen and Boss). Treated phenomenologically, we understand intentionality as a fundamental feature of a consciousness; we judge it to be sustainable that this structure enables a different interpretation of the psyche that promoted by the traditional reading that reduces consciousness to the subject. Considering the intentionality the structure that allows immediate correlation of consciousness with its phenomena, we should judge Daseinanalyse, understood as phenomenological psychology and psychopathology, phenomenological psychology and psychopathology, has viability only in the space opened by the intentional consciousness.

Keywords: consciousness, intentionality, Daseinanalyse, Heidegger. 


\section{Introdução}

O artigo assume por tema a intencionalidade no âmbito da Daseinanalyse; questiona, assim, qual o estatuto que essa estrutura intencional possuiria no âmbito de uma psicologia fundada em bases fenomenológicas. Para tratar o referido tema, visando responder o problema que dele deriva, o trabalho cumprirá três tarefas: conceituar a estrutura da intencionalidade à luz da fenomenologia; . reconstruir brevemente sua gênese conceitual junto a Brentano, Husserl e Heidegger ;

. e, principalmente, indicar a presença desta ideia na obra de autores como Binswanger e Boss.

Compreendendo a intencionalidade como traço fundamental da consciência, julgamos poder entrever que a intencionalidade viabiliza uma interpretação do psiquismo diversa daquela promovida pela leitura tradicional que reduz a consciência a sujeito.

Portanto, com a intencionalidade, a fenomenologia redefine 0 estatuto da consciência tanto no plano da filosofia, quanto no plano da psicologia, uma vez que tal estrutura permite evidenciar que a consciência não é interioridade cerrada, a qual constituiria sede para estruturas e processos psíquicos, tampouco, polo subjetivo de caráter receptor e reflexivo dos fenômenos exteriores.

Isto não apenas oportunizaria, para a filosofia, uma revisão do modelo metafísico que referenda a dicotomia entre sujeito-objeto, mas, também, reforma a posição da psicologia segundo a qual o sujeito sediaria o psiquismo. O que se revelará com isso é uma relação imediata da consciência com seus fenômenos correlatos em um espaço intencional no qual uma psicologia fenomenológica se faz possível.

\section{Ideias diretrizes para uma "psicologia sem psique".}

[...] o existir humano em seu fundamento essencial nunca é apenas um objeto simplesmente presente num lugar qualquer, e certamente não é um objeto encerrado em si. Ao contrário, este exigir consiste de 'meras' possibilidades de apreensão que apontam ao que se fala e o encontra e não podem ser apreendidas pela visão ou pelo tato. Todas as representações encapsuladas objetivantes de uma psique, um sujeito, uma pessoa, um eu, uma consciência, usadas até hoje na psicologia e na psicopatologia, devem desaparecer na visão daseinanalítica em favor de uma compreensão completamente diferente. (HEIDEGGER, 2001, p.33)

Todos conhecemos essas linhas, tomadas de ditado de Martin Heidegger (1889-1976). Elas iniciam os Seminários de Zollikon. Se 
bem lembrarmos, nos protocolos da primeira sessão dos seminários (datada de 8 de setembro de 1959), Heidegger ilustra com semicírculos e setas o que ele entenderia como o objeto da assim chamada Daseinanalyse. Em semicírculos e setas temos ali o Dasein, o ser-aí. Na filosofia clássica alemã, o termo ser-aí é indicativo de uma experiência de simples presença. É com esse significado que o encontramos na filosofia de Jacobi, de Kant e, mesmo, em Hegel. Heidegger, entretanto, diante das necessidades de nomear a figura de consciência em pauta nas suas pesquisas programáticas de fenomenologia, acaba por se apropriar diferenciadamente da expressão ser-aí (Dasein). Tal escolha ocorre mediante a ponderação de três fatores:

1. a constatação de que o conceito de facticidade, presente no seu projeto de uma hermenêutica da vida fática (e em vigor em seus escritos de 1922-25) não compreende fenômeno mais amplo que será, futuramente, alvo de sua analítica existencial;

2. a hesitação em adotar o conceito de homem, temendo atrair para si todos os inconvenientes de uma tradição que o compreenderia como vivente essencialmente racional, denotando, assim, um ente dotado de substancialidade, de quididade;

3. a impossibilidade de optar sem reservas pelo conceito diltheyano de vida em épocas nas quais também este se encontra eivado pelas concepções de escolas como o vitalismo de Hans Driesch e o biologismo de Ludwig Klages.

Sendo assim, com o termo ser-aí, Heidegger entende um ser situado no mundo, um ser que possui um mundo por correlato, correlato este sem o qual ele próprio nada seria. Esta compreensão é completamente diferente das demais referidas.

Diante tão somente do que foi dito até aqui, asseveramos que o esquema apresentado por Heidegger no primeiro encontro em Zollikon ilustra bem essa negatividade possível do ente em questão. O ser-aí é este que não possui essência, substancialidade ou quididade $e$, quando pensado como um semicírculo, deixa transparecer que é uma experiência em aberto, um ser inacabado e, portanto, muito diverso da condição de um objeto subsistentemente dado. Apresentando-o como "obra aberta", Heidegger pretende evidenciar que o ser-aí não consiste na experiência ôntica de um sujeito, de uma subjetividade, de um ego substancialmente estabelecido; daí o comentário que reforça a necessidade de abdicar das interpretações objetivantes que redundariam num ego encapsulado, numa subjetividade inserida na dicotomia sujeitoobjeto; daí, a prescrição de abandonar essas ideias caras aos 
modelos da psicologia e da psicopatologia em prol de um olhar daseinanalítico, fenomenológico, portanto.

Sob um primeiro olhar, a diretiva de Heidegger em favor de uma psicologia em bases fenomenológicas ${ }^{1}$ cobra um alto preço e não oferece qualquer garantia. Uma avaliação daquela situação hermenêutica nos mostraria que abrir mão da ideia de sujeito significa renegar tudo o que a psicologia auferira até então e, se não desejarmos retroagir às origens metafísicas da psicologia com Platão e Aristóteles, conservando-nos no âmbito de uma psicologia científica, é possível constatar que mesmo as bases psicofísicas lançadas por autores como Fechner, Wundt e Titchner (bases estas com presença vestigial na psicanálise freudiana e nos esboços de psiquiatria fenomenológica de Jaspers) seriam sobremaneira abaladas. Em troca disso, o que teríamos de uma psicologia fenomenológica aos moldes heideggerianos? Uma psicologia que não parte da consideração de um sujeito hipotético (hipostasiado), em outras palavras: uma psicologia sem psique. É isto que o filósofo chamou na citação inicial de uma psicologia e psicopatologia em uma compreensão completamente diferente; é esse o ponto de partida de uma clínica psicológica que nos situa "de uma maneira diferente tanto diante do logos como da psique [...]" (POMPEIA; SAPIENZA, 2011, p.150).

Sob um segundo olhar, o que parece ser uma carência da fenomenologia (e, por extensão, da Daseinanalyse) é, em verdade, o que lhe assegura, desde o início, o ver e o agir fenomenológicos antes mesmo que qualquer procedimento normativo ou metodologia possam pretender legitimidade. Assim, enquanto muitos entendem perder com a fenomenologia, seus estudiosos entendem que o maior ganho que se pode ter na lida com os fenômenos (e neste caso os fenômenos do "psiquismo") provém do ato de não apreende-los de maneira objetivada, hipostasiada por um ver que se faz desatento ao movimento da consciência em autoinspeção. Daí, se até agora falamos dos semicírculos presentes no esquema heideggeriano que ilustra o ser-aí naqueles seminários, descrevamos desde aqui o que está em jogo nas setas que, de maneira igualmente decisiva, compõem o diagrama. Este novo passo, além de oportunizar a retomada de pontos ainda obscuros na descrição anterior, introduzirá em nosso texto o conceito de intencionalidade, tal qual anunciado em nosso título.

\section{Intencionalidade, estrutura fenomenológica fundamental}

De início, podemos entender a Daseinanalyse como a tentativa dos psiquiatras Ludwig Binswanger (1881-1966) e Medard Boss (19031990) em apropriar a filosofia de Martin Heidegger para pensar a 
psicanálise (RICHARDSON, 2003). O próprio Boss, no prefácio à primeira edição dos Seminários de Zollikon, admite que o contato com a obra Ser e tempo (1927), durante a Segunda Guerra, foi o que instigou suas primeiras pesquisas nesse sentido. O autor reconhecia na analítica existencial de Ser e tempo "insights fundamentalmente novos e inauditos no existir humano e seu mundo" (BOSS, 2001, p.10). Embora contendo inegavelmente contribuições originais, é preciso reconhecer que a filosofia de Heidegger, neste período, se encontra indissociavelmente ligada à fenomenologia de Edmund Husserl (1859-1938), sendo debitária de algumas de suas intuições primordiais. Com Husserl, Heidegger aprendeu o método fenomenológico (depois depurado na forma de atitude fenomenológica) e a estrutura que permite este agir orientado pelos fenômenos. A referida estrutura: a intencionalidade.

Uma advertência deve ser dada aqui antes mesmo que o termo intencionalidade seja introduzido conceitualmente: o que Husserl e Heidegger compreendem com o termo em nada tem a ver com intento, fito ou propósito voluntário. Essa nota, que soaria elementar aos familiarizados com a terminologia fenomenológica, não parece dispensável aos que buscam compreender a intencionalidade no âmbito da psicologia. De sorte que, mesmo Ludwig Binswanger, preocupado com ambiguidade que o termo poderia acarretar, ressalva:

Há que se esclarecer que nem a intentio, nem nenhuma de suas derivações tem que ver com atenção, atividade, nem com nada parecido. O intento significa aqui apenas a direção ou a relação da consciência com 'algo'[...]; a intencionalidade significa aquilo para o que nos dirigimos animicamente. (BINSWANGER, 1973, p.26).

A noção de intencionalidade, sobre a qual a fenomenologia se apoia, se edifica tendo em vista a correspondência que uma figura de consciência sempre possui com o fenômeno que objetivamente se the encontra correlato, mas que, por sua vez, também só se constitui em meio ao acontecimento da intencionalidade (HEIDEGGER, 1992). Para o autor, a experiência humana é consciência e, por sua vez, consciência é sempre consciência de algo, é como nos diz Husserl (1962, p. 168): "na percepção de um percebido, na imaginação de um imaginado, na enunciação de um enunciado, no amor de algo amado, [...] no desejo de um desejado etc". Com este trecho das Investigações lógicas, se ilustra o que, anteriormente, já falando em ser-aí, tratamos por "correlação"; tanto Binswanger (1953) quanto Boss (1963) enfatizam incessantemente esta correlação em suas obras. Como dissemos adiante, a correlação desses dois polos em questão descreve fundamentalmente a impossibilidade de atos de consciência que se façam na ausência de objetos; do mesmo modo, 
ela também implica a impossibilidade de campos objetuais sem a correlação com fenômenos da consciência (HUSSERL, 1963).

Como nos lembra Binswanger (1973), a fenomenologia de Husserl se move na sutil fronteira entre a lógica e a psicologia, descrevendo que o conhecimento possível dos entes se encontra intimamente ligado a atos da consciência fenomenológica e não consistindo, portanto, em um produto de representações de um sujeito que trava relação com objetos exteriores. Afirmando que objetos são imanentes à consciência, Husserl busca reatar, fenomenologicamente, o laço da consciência com o mundo objetivo possível, grifando a relação intencional de base indicativa de que todo conhecimento é constituído (conhecido) em atos de conhecer, ou ainda, que todo "ato de conhecer é uma objetivação do ente na medida em que ele é na consciência" (LAUER, 1955, p. 80). Esta imanência garante à fenomenologia o conhecimento metódico, absolutamente fundado em evidências fenomenológicas dos objetos; nestes termos se traduz a apoditicidade típica, importante e largamente explorada no interior do projeto husserliano de uma filosofia rigorosa (MOHANTY, 1995). Para que a fenomenologia obtivesse tal certeza apodítica, foi preciso que Husserl investisse na estrutura da intencionalidade. Tal conceito corresponde paradigmaticamente ao que Heidegger compreende como as setas no seu esquema ilustrativo do ser-aí.

Originada na Escolástica medieval, esta noção, anos antes, havia sido reapropriada por Franz Brentano em sua Psicologia de um ponto de vista empírico (1864). Ali, a intencionalidade permitiria a referência a conteúdos de consciência, objetos imanentes classificados à luz dessa psicologia descritiva como fenômenos psíquicos (PRECHTL, 1989). Seguido de perto por seu discípulo Karl Stumpf (1848-1936), Brentano concentra-se em atos psíquicos como representações, juízos e emoções; no entanto, ao fazer isso, deixa inexplorada aquela estrutura de base: Brentano negligencia o que seria seu achado mais precioso do ponto de vista fenomenológico (por este motivo não se pode vincular Brentano, tampouco Stumpf, conforme erroneamente se tem feito, à fenomenologia; a associação mais plausível a ambos é à psicologia descritiva) (SCHÉRER, 1969).

Ao ater-se à intencionalidade, Husserl valoriza nela o que ficou impensado em seus predecessores; ele mostra que a intencionalidade propicia clareza quanto à constituição de campos de aparição dos objetos, estes que não se manifestam mediante representação, mas na intuição de suas idealidades, isto é, aparecendo tal qual é dado, o objeto evidencia o que em si mesmo há de mais essencial. Assim, para Husserl (1992), o modo com que intencionalmente a consciência atua permite, verdadeiramente, a percepção dos objetos (LAUER, 1955). Ao desenvolver o conceito de intencionalidade, Husserl pode agora (trilhando as vias do método fenomenológico) evidenciar que as vivências da consciência em atitude natural têm esta estrutura 
fenomenal obstruída, tomando, por conseguinte, os campos objetuais abertos pela intencionalidade de maneira confusa e simplificada (quadro que se estende, até mesmo, para as investigações com pretensões psicológicas). A fenomenologia indica que essa ambiguidade adquirira proximidade tamanha a ponto de ser tomada como "natural". De igual modo, esta atitude também desconsidera reiteradamente o elemento intencional que a fenomenologia tem em vista, assumindo, assim, uma postura ingênua com relação ao objeto, qual seja: aquela que nos leva à sólida convicção de que o conhecimento é constituído a partir da relação empírica de um sujeito autônomo (dado a priori e dotado de aparato psíquico) com entes de presença constante, independente e reificável.

Na contramão dessa tendência, a análise rigorosa da intencionalidade de um ponto de vista fenomenológico permite-nos compreender 0 caráter transcendente dos atos de consciência e, a partir desses, os campos nos quais os entes já se mostram desde sempre como correlatos noemáticos à consciência. Daí, suspender (por meio de um procedimento chamado "epoché") os efeitos hipostasiantes e obstrutivos da atitude natural, decompor conglomerados de atos de consciência em caracteres intencionais primitivos, descrever a essência pura e transcendental das vivências e analisar os laços necessários que a consciência possui com seus objetos são tarefas precípuas da fenomenologia husserliana (HUSSERL, 1962). Heidegger, entretanto, entende que há algo de urgente ainda em pauta: aprofundar o achado fenomenológico que é a intencionalidade, levando-o a uma instância mais radical do que teria pensado Husserl. $^{2}$

Com a licença de não aderir aos novos rumos da fenomenologia de seu mestre estabelecidos em seu Ideias diretrizes para uma fenomenologia pura (1910-13), Heidegger entende que mais importante do que tratar a gênese e as operações transcendentes de uma subjetividade sintetizadora de vivências seria compreender as ligações de sentido que denotam a implicação entre o polo equivalente à consciência e seus correlatos. É assim que entra em cena a noção de ser-aí.

\section{Ser-aí e intencionalidade}

Não é simples a tarefa de uma caracterização do ser-aí. Uma primeira aproximação deste fenômeno deixa logo claro que mais fácil do que predicá-lo, seria dizer o que ele não é, caracterização negativa que nos traria alguma clareza quanto ao ser-aí. Daí, começarmos indicando que o ser-aí não corresponde ao modo de ser da mera coisa (HEIDEGGER, 1993), uma vez que, implícito nesta noção, aparentemente neutra, identificaríamos as propriedades realidade e 
"coisidade" (categorias influentes nas ontologias tradicionais na medida em que interferem em suas interpretações metafísicas do ser). Tomando estritamente, o ser-aí "não é um ente que ocorre entre outros" (HEIDEGGER, 1993, p.12), um ente que possuiria entidade ou quididade (quidditas), de sorte que nem a designação de ente (entendido como elemento de um domínio objetivo) traduz precisamente o modo de ser do ser-aí. A negativa dos argumentos anteriores cabe, por extensão, à interpretação derivada de ente enquanto "criatura" (ens creatum). O ser do ser-aí tampouco se constitui como animal rationale, pois, para Heidegger, "esta determinação não é apenas a tradução latina do zõon lógon ekhon grego, mas uma interpretação metafísica" (HEIDEGGER, 1967, p.153) que remonta, uma vez mais, à ideia de substancialidade expressa na chave do gênero supremo-diferença específica (HEIDEGGER, 1988). Por fim, mesmo a denominação de objeto resulta inadequada para uma caracterização rigorosa do ser-aí, isso porque a palavra objeto pressupõe algo posto ou lançado defronte a um sujeito para quem esse algo impõe resistência. ${ }^{3} \mathrm{O}$ pensamento que naturalmente julga poder assumir essas premissas move-se ainda no interior da dicotomia sujeito-objeto, expondo-se a todas as implicações metafísicas que o modelo tradicional oferece.

O descrito acima é o que poderíamos identificar como o resultado da apropriação heideggeriana do gesto inaugural, decisivo e contínuo que é a epoché fenomenológica (ato que suspende a validade de conteúdos das duas referidas tendências teórico-hipostasiantes). No presente caso, Heidegger, considerando e radicalizando a epoché fenomenológica, acaba por submeter a própria consciência intencional à redução. Isso porque, para um Heidegger tão intransigente quanto atento ao modus operandi da fenomenologia, conservar a subjetividade, ainda que refinadamente pensada como subjetividade sintetizadora de vivências, é expor-se ao risco da noção de sujeito realojar-se sub-repticiamente nessa, de modo que seria possível indicar que, na fenomenologia de Husserl, esta noção, "enquanto não passar por uma elucidação prévia de sua determinação ontológica fundamental," (HEIDEGGER, 1993, p.46) reteria ainda um resquício subjetivo.

Deste modo, o efeito da epoché heideggeriana suspende mesmo a validade da consciência (ego, cogito), esta, que ainda resguardava um atributo substancial, é passível de ser apontada como uma última determinação metafísica do ente que antes caracterizamos negativamente como ser-aí. ${ }^{4}$

Os leitores devem estar se perguntando: o que resta para chamarmos de ser-aí, depois de um movimento como esse? O que permanece do ser-no-mundo para empreendermos uma analítica existencial e, por extensão, uma Daseinanalyse? A epoché estendida 
à consciência põe-nos diante da evidência de um espaço fenomenal constituído no interior do qual o ser-aí se relaciona com os fenômenos; antes disso, nos coloca diante do ser-aí como um poderser (RICHARDSON, 2003). Isto significa que não sendo sujeito, consciência ou ego, o ser-aí é este marcado pelo caráter de poderser, de sorte que se algo pode ser propriamente dito sobre este ente é o fato de ele poder ser. Isso se torna ainda mais claro nas palavras de Heidegger: "Ser-aí não é um simplesmente dado que tem, adicionalmente, o poder de ser alguma coisa. Ele, primariamente, é possibilidade de ser". (HEIDEGGER, 1993, p.143). Neste momento, contudo, mais importante do que reafirmar a existência em aberto do ser-aí por meio da ideia de poder-ser, é indicar o espaço de possibilidades deste ente aberto na intencionalidade.

Na filosofia de Heidegger, como já vimos, o ser-aí é correspondente fático de uma figura de consciência, figura correlata a um campo objetual que a ele se abre. Na referida correlação, a intencionalidade se revela como a estrutura necessária à correlação entre o ser-aí e os campos de objetos. Diferentemente de Husserl, Heidegger inscreve a intencionalidade na dinâmica da existência do ser-no-mundo, passa ela, assim, a ser compreendida no âmbito existencial do ser-aí e segundo as interpretações que tal ente faz de sua existência e de seu mundo. Assim pensada nos domínios de uma analítica existencial, a intencionalidade é compreendida como constituinte do horizonte de realização do ser-no-mundo, isto é, do espaço no qual os entes se manifestam, da projeção de sentidos possíveis e da determinação de significados dos fenômenos mundanos. Dito isso, podemos depreender que, de um ponto de vista fenomenológico, é a intencionalidade que nos permite compreender 0 caráter transcendente dos atos de consciência e, a partir desses, os campos fenomenais nos quais os entes já se mostram como tal (HALL, 1993). Mesmo pensado como uma malha relacional em que se estruturam campos objetuais a partir dos quais se subministram os entes manifestos, o mundo do ser-aí, tal como pensando por Heidegger, conserva a correlação intencional. Isso significa que a estrutura da intencionalidade continua operante na analítica existencial e, apesar de a intencionalidade estar pouco visível (devido a Heidegger, no interior de seu exame do ser-no-mundo, tê-la reestruturado na forma existencial de compreensão voltada à complexidade do mundo), não significa, em nenhum momento, que o filósofo tenha perdido de vista esta estrutura fundamental. Não seria exagero chamar a intencionalidade de estrutura fundamental, afinal, ela é pressuposto da psicologia descritiva de Brentano, orientando, também, o fazer da fenomenologia husserliana, da analítica existencial de Heidegger e da Daseinanalyse, na conexão entre Binswanger e Boss. Com esta afirmativa, chegamos ao ponto central de nosso trabalho, que é a 
afirmação segundo a qual uma psicologia em bases fenomenológicas depende, necessariamente, da intencionalidade.

Ora, mas por que a Daseinanalyse dependeria da estrutura da intencionalidade? Precisamente pelo fato de os comportamentos, afetos e, mesmo, patologias do ser-aí (e neste caso mesmo indícios psicopatológicos possíveis a este ente) já sempre se manifestarem em campos fenomenais intencionalmente abertos, neste caso, no horizonte constitutivo de um mundo. Ao reestruturar a intencionalidade existencialmente, Heidegger permite que o ser-nomundo seja evidenciado na chave intencional, uma vez que essa noção traduz o ente que se manifesta num espaço fenomenal. Assim, uma psicologia em bases fenomenológicas ao descrever e analisar os fenômenos constituídos no interior dos espaços de jogo do ser-aí, já pressupõe a estrutura de base da intencionalidade, esta atuante na forma da compreensão do ser-aí. Isso reforça o fato de que qualquer psicologia ou psicoterapia fenomenológica precisaria contemplar seus fenômenos na correlação intencional, ou seja: considerar um desejar em face do que se mostra desejado, um amar (ou odiar) ao que se Ihe mostra amado (ou odiado), do sonhar ao que se lhe mostra sonhado... (BINSWANGER, 1973; BOSS, 1979).

\section{Da apropriação daseinanalítica do conceito de intencionalidade em Binswanger e Boss}

Indícios da apropriação daseinanalítica da intencionalidade estão por toda parte na obra de Ludwig Binswanger e de Medard Boss. A presente comunicação, após toda a exposição conceitual da referida estrutura, se limitará a indicar alguns modos com os quais estes autores contemplam a intencionalidade em suas investigações.

Binswanger (que na década de 1920 manteve contato com Heidegger na Universidade de Marbourg e foi correspondente de Freud) sabe a fenomenologia tal, como define Husserl (1961, p.21), como uma "psicologia descritiva das vivências puras". Contudo, o psicoterapeuta entende necessário esclarecer que a Daseinanalyse, enquanto fenomenologia, ao mover-se no horizonte da intencionalidade, ocupando-se com sintomas concretos distintos e perceptíveis na psiquiatria, psicopatologia e psicoterapia, difere quanto a seu escopo da investigação das essências de Husserl, bem como em sua metodologia da psicologia descritiva. Deste modo,

trata-se aqui de uma fenomenologia que, ainda que não alcance as alturas da essência pura, não deve se confundir com o que se chama, em relação à psicologia descritiva, de psicopatologia descritiva ou subjetiva, o que tornaria a fenomenologia psicopatológica quase por completo incompreendida (BINSWANGER, 1973, p. 32). 
Feitas essas ressalvas, o autor ainda reforça que, se pensada a Daseinanalyse como psicologia fenomenológica, esta necessita das diferentes descrições de numerosos fenômenos patológicos apenas possíveis desde o espaço fenomenológico aberto na dinâmica intencional; garantindo, assim, à psicopatologia uma compreensão sempre esclarecida e renovada, por exemplo, da ideia delirante, da alucinação, do autismo etc. Em sua abordagem, o autor tem também em vista o fato de que a psicopatologia se perfaz diante da consideração do outro. Isto quer dizer que, para Binswanger (1973), "o fundamento da psicopatologia é basicamente a percepção de um eu outro ou de outro eu [...]" (p.33). Deste modo, não se pode compreender o objeto da Daseinanalyse como sendo estruturas internas de uma suposta subjetividade explicada por uma teoria, mas como o que é percebido quando, em atitude fenomenológica, nos voltamos à vida anímica de uma pessoa. ${ }^{5}$ Assim, o essencial na observação fenomenológica das psicopatologias são os fenômenos no horizonte da experiência humana ou, dizendo de outra maneira, o que importa à Daseinanalyse é o que se manifesta de tal ou qual modo no horizonte fenomenal do ser-aí. O ser-aí afetado por uma patologia se manifesta, neste caso, desde um fenômeno específico e a Daseinanalyse, por sua vez, tem o fenômeno patológico no horizonte intencional do ser-aí afetado. Esta relação aparece sintetizada por Ernest Keen, que a tendo compreendido bem, remata nossa exposição de Binswanger ao afirmar que:

[...] a abordagem de Binswanger não é uma técnica para revelar horizontes internos de experiência; ao contrário, é uma teoria relativa a horizontes que estão universalmente presentes na experiência humana. É uma filosofia do homem, dos estados de humor e da terapia (KEEN, 1979, p. 55).

Como Binswanger, Boss guardava profundo apreço por Sigmund Freud (1856-1939), isto, entretanto, não impediu que esse contestasse, à luz da fenomenologia, muitas das ideias das teorias explicativas freudianas. A nosso ver, a ideia de uma subjetividade dotada de aparelho psíquico e regida por leis naturais, ainda presente na psicanálise de Freud, era o principal alvo de objeções de uma psicologia fenomenológica. Isso porque, a metapsicologia de Freud ainda recorria a um sujeito hipostasiado para estabelecer suas explicações e classificações, esforço que consiste na interpretação de elementos psíquicos diante de um rol de hipóteses empiricamente verificáveis (GUIGNON, 1993).

Partindo do paradigma fenomenológico, para o qual a intencionalidade é estrutura envolvida na evidenciação dos fenômenos (também de uma figura de consciência correlata, aqui 
assumida como o ser-aí), e reconsiderando todo o movimento de exposição do ser-aí, por nós elaborado, como um ser desprovido de subjetividade, não mais seria possível acatar a ideia de uma subjetividade simplesmente presente, recipiente, reflexiva e que se desempenha encapsulada em si. Consoante a Heidegger, Boss nos garante isso ao afirmar que:

não há prova, nos fenômenos reais da existência humana, da existência de entes endopsíquicos tais como representações, ou afetos a eles ligados. Ainda assim, nem sequer a mais importante condição prévia para estas premissas foi até agora explicada: ninguém sabe onde está ou o que é este recipiente "psíquico" ao qual a palavra dentro se refere. Se a resposta é "dentro" de uma psique, faz-se necessário demonstrar primeiro que nós seres humanos possuímos psiques, entes que existem em alguma parte acessível em algum espaço vazio. Em segundo lugar, precisaríamos saber a natureza desta psique dentro de qual "afetos" e representações do mundo exterior poderiam penetrar, como se ele fosse uma cápsula (BOSS, 1979, p. 45).

Diante da força deste argumento, se nos deixarmos orientar tão somente pela atitude fenomenológica ou daseinanalítica atendo-nos exclusivamente aos fenômenos da existência do ser-aí, depreenderíamos que as teorias de faculdades e muitas de suas respectivas inferências não poderiam ser endossadas pela Daseinanalyse. Isso, porque (como ensina Husserl), toda teoria (e no presente caso se insere a psicanálise freudiana), se move apoiandose em hipostasias, de sorte que suas premissas reproduziriam a ingenuidade intrínseca a esta pressuposição inicial. A fenomenologia, que consiste em um procedimento apenas descritivo e, portanto, não teorizante, seria assim via privilegiada para compreender elementos do psiquismo sem adulterá-los com especulações e interpretações.

Medard Boss nos dá prova eloquente de como a fenomenologia pode apropriar validamente intuições da psicanálise sem transigir com um sujeito tradicionalmente concebido. Trata-se de uma hermenêutica dos sonhos que toma o ser-aí como agente sonhador. Para Boss (1979, p.44), esses "exercícios práticos de compreensão fenomenológica dos elementos oníricos" são capazes de evitar a distorção dos fenômenos sonhados mediante teorizações e especulações uma vez que não mais presume significados ocultos em uma faculdade inconsciente. Nosso autor sabe que nada há para ser perscrutado atrás dos significados que se revelam a nós diretamente dos fenômenos oníricos, deste modo, evidencia que, mesmo durante o sonho, a intencionalidade permanece atuante, o que nos faz crer que o espaço onírico não é outro senão um caso do horizonte fenomenal do ser-aí em vigília (BOSS, 1963). Isto nos garante Boss (1979) quando propõe que a "experiência de sonhar pertence à 
existência tanto quanto a sua vida desperta, [...] que a sua sujeição às coisas que encontra [...] não só existe no seu mundo como uma relação [...] ao externo, mas também como traço característico de sua própria existência" (p. 42).

Dito isso, a Daseinanalyse com Boss empreende um exercício de compreensão dos sonhos, de modo que os fenômenos do mundo do sonho se conservem exatamente como são quando se revelam ao ser-aí sonhador. Isto porque,

\begin{abstract}
livres dos acréscimos supérfluos e enganosos das modernas teorias psicologísticas do sonho, estaremos prontos a começar o treinamento para uma visão não distorcida do serno-mundo de seres humanos que sonham. Uma abordagem tão simples é com frequência criticada como "banal", mas [...] esta crítica recai sobre os próprios críticos, pessoas que se tornaram cegas à riqueza de significado existente em cada fenômeno que encontramos, seja acordados ou sonhando. (BOSS, 1979, p. 43).
\end{abstract}

Mais do que o empenho de levar ao cabo, com a Daseinanalyse, o "slogan" fenomenológico: às coisas elas mesmas, presenciamos aqui o acuro de Boss em cultivar um ver capaz de perceber, avaliar e cuidar da riqueza da experiência humana na indigência do ser-aí. Um olhar que, orientado pela intencionalidade, acompanha sua própria transcendência podendo descrever 0 que nela se manifesta; denunciando as limitações e tendências derivadas que nos leva a interpretações desviantes da experiência de nossa inerente simplicidade. Ao investigar o sonho, o desejo, a lembrança e outros fenômenos que nada têm de endopsíquicos (como pressuporiam as teorias psicologísticas), também Boss evidenciou que todo sonhar, desejar, lembrar é inerentemente um sonhar, desejar, lembrar de alguma coisa. Isto significa que qualquer um desses comportamentos nos remete a um modo específico de relacionar-se inteiramente com algum fenômeno numa base intencional, o que, por si só, evidencia (como se vê junto aos demais autores da Daseinanalyse) a importância da intencionalidade.

\title{
6 Considerações finais
}

Tendo conceituado a intencionalidade, à luz da fenomenologia husserliana, como traço fundamental da consciência, grande parte do esforço de nosso artigo foi o de indicar que a consciência intencional abre campos fenomenais nos quais os entes se manifestam; por sua vez, o manifesto nestes campos fenomenais é descrito pela fenomenologia. Buscamos mostrar, também, que insatisfeito com os rumos da fenomenologia transcendental de Husserl, Heidegger 
elaborou uma síntese própria da fenomenologia, colocando sob efeito da suspensão fenomenológica a própria consciência. O resultado disso é um ente marcado pelo caráter ontológico da possibilidade, um ser que possui seu próprio mundo como correlato determinante e que tem a intencionalidade enfeixada em suas muitas demandas existenciais. Ao dissolver os últimos delineamentos da consciência intencional na forma de ser-aí, Heidegger tornou possível para Binswanger e Boss uma psicologia sem psiquismo, uma psicologia em bases fenomenológicas, ou ainda em uma Daseinanalyse. Com esta, é possível descrever, analisar e cuidar do ser-aí sem que este seja abordado como um sujeito estabelecido, do mesmo modo, é possível ter acesso a seus fenômenos "psíquicos" sem precisar, para tanto, recorrer a teorias explicativas do sujeito, geralmente adulterantes dos objetos da psicologia, psicoterapia e psicopatologia. Tendo a estrutura da intencionalidade na pedra de toque da fenomenologia e, ainda, na pauta de uma Daseinanalyse, é possível acessar os comportamentos, afetos e patologias do ser-aí como fenômenos e como tais fenômenos aparecem significativamente para o outro. Assim, se com a psicologia em bases fenomenológicas de Binswanger e Boss, não auferimos a apoditicidade do conhecer tão ansiada por Husserl, nos parece lícito afirmar que a Daseinanalyse nos evidencia os fenômenos no horizonte em que se constitui a experiência humana, em suas múltiplas possibilidades.

\section{Referências}

BINSWANGER, L. Artículos y conferencias escogidas. Trad. Mariano Marin Casero. Madrid: Gredos, 1973.

\section{Grundformen und erkenntnis menschlichen daseins.}

Zurich: Neihans, 1953.

BOSS, M. Na noite passada eu sonhei... Trad. George Schlesinger. São Paulo: Summus, 1979.

. Prefácio à primeira edição. In:

(Org.). Seminários

de Zollikon. Medard Boss. Trad. Gabriella Arnhold; Maria de Fátima de Almeida Prado. Petrópolis: Vozes, 2001. p. 9-16.

Psychoanalysis and daseinanalysis. New York: Basic

Books, 1963.

BRENTANO, F. Psychologie vom empirischen Standpunkt. Leipzig: Duncker \& Humbolt, 1874.

DREYFUS, H. L. Heidegger's critique of Husserl's (and Searle's) Account of Intentionality. Social Research, s/l., s/ed. n. 60, v. 1, p. 17-38, winter 1993.

GUIGNON, C. B. Authenticity, moral values, and psychotherapy. In: GUIGNON, C. (Org.). The Cambridge companion to Heidegger. New York: Cambridge University Press, 1993. p. 215-239. 
HALL, H. Intentionality and world: Division I of Being and time. In: The Cambridge companion to Heidegger. GUIGNON, C. (Org.). New York: Cambridge University Press, 1993. p. 122-140. HEIDEGGER, $M$. Brief über den Humanismus. In: Wegmarken. Frankfurt am Main: Vittorio Klostermann, 1967, p. 145-194.

History of the concept of time: Prolegomena. Trad. Theodore Kisiel, Bloomington, Indianapolis: Indiana University Press, 1992.

. Ontologie: hermeneutik der faktizität. In: Gesamtausgabe II. Abteilung: Vorlesungen. Band 63. Frankfurt am Main: Vittorio Klostermann, 1988.

.; BOSS, M. (Org.). Seminários de Zollikon. Trad. Gabriella Arnhold; Maria de Fátima de Almeida Prado. Petrópolis: Vozes, 2001.

. Sein und Zeit. 17. ed. Tübingen: Max Niemeyer, 1993. HUSSERL, E. Cartesianische Meditationen. In: STRÖKER, E. (Org.). Gesammelte Schriften. Band. VIII. Hamburg: Felix Meiner, 1992. p. 3-161.

Recherches logiques: Recherches pour la phénoménologie et la théorie de la connaissance. Vol.II. Première partie. Trad. Hubert Élie et al. Paris: PUF, 1961.

Recherches logiques: Recherches pour la phénoménologie et la théorie de la connaissance. Vol.II. Deuxième partie. Trad. Hubert Élie et al. Paris: PUF, 1962.

Recherches logiques: Éléments d'une élucidation phénoménologique de la connaissance. Vol.III. Trad. Hubert Élie et al. Paris: PUF, 1963.

KEEN, E. Introdução à psicologia fenomenológica. Trad. Eliana de Barros Conde Rodrigues. Rio de Janeiro: Interamericana, 1979.

LAUER, Q. Phénoménologie de Husserl: Essai sur la genése de I'intentionnalité. Paris: PUF, 1955.

MOHANTY, N. The development of Husserl's thought. In: SMITH, B.; SMITH, D. W. (Orgs.). The Cambridge companion to Husserl. New York: Cambridge University Press, 1995. p. 45-77.

MORAN, D. Heidegger's critique of Husserl's and Brentano's Account of Intentionality. In: Inquirity. New York: Taylor \& Francis, n. 43. p. 39-66, winter 2000.

POMPEIA, J. A.; SAPIENZA, B. T. Os dois nascimentos do homem: Escritos sobre terapia e educação na era da técnica. Rio de Janeiro: Via verita, 2011.

PRECHTL, P. Die Struktur der "Intentionalität" bei Brentano und Husserl. In: BAUMGARTNER, W.; BURKART, F-P.; WIEDMANN, F. (Orgs.). Brentano Studien - Internationales Jahrbuch der Franz Brentano Forschung. Würzburg, v. 2, n. 2, p. 117-130, 1989.

Heidegger: Through phenomenology to thought. The Hague: Martius Nijhoff, 1967. 
Seminário de Zollikon de Martin Heidegger - Analítica do ser-aí e Psicanálise. (Protocolos de curso ministrado durante os dias 09-11 de junho de 2003) - Universidade do Estado do Rio de Janeiro, Rio de Janeiro.

SCHÉRER, R. La fenomenología de las "investigaciones lógicas" de Husserl. Trad. Jesús Diaz. Madrid: Gredos, 1969.

\section{Endereço para correspondência}

Roberto S. Kahlmeyer-Mertens

Rua São Francisco Xavier, 524, Pavilhão - João Lyra Filho, 9 andar, Bloco F, sala 9037, Maracanã, Rio de Janeiro, RJ - Cep: 20550-013

Endereço eletrônico: kahlmeyermertens@gmail.com

Recebido em: 09/11/2011

Aceito para publicação em: 30/11/2012

Acompanhamento do processo editorial: Ana Maria Lopez Calvo de Feijoo

\section{Notas}

*Doutor em filosofia pela Universidade do Estado do Rio de Janeiro - UERJ. Membro efetivo da Sociedade Brasileira de Fenomenologia - SBF

${ }^{1}$ O que, grosso modo, tomamos como sinônimo de Daseinanalyse.

${ }^{2}$ Veja-se mais a este respeito em Dreyfus (1993); Moran (2000).

3Para essas duas acepções, reservam-se os termos "gegenstand" e "gegenwurf", respectivamente.

${ }^{4}$ Após este argumento, não é preciso dizer, que o ser-aí não é apenas uma palavra para substituir consciência, tampouco a representa: trata-se de um ente pensado num contexto radicalmente diverso do antropológico e mesmo do psicológico.

${ }^{5}$ Nesse ponto, Binswanger (1973) nos lembra que mais teria a contribuir com uma fenomenologia psicopatológica as investigações minuciosas sobre o fenômeno da simpatia elaboradas por fenomenólogos como Max Scheler, do que as teorias das escolas associacionistas. 